\title{
MEMS-BASED QUARTZ OSCILLATORS and FILTERS for on-CHIP INTEGRATION
}

\author{
R. L. Kubena, F. P. Stratton, D. T. Chang, \\ R. J. Joyce, and T. Y. Hsu \\ Sensors and Materials Laboratory, HRL Laboratories, LLC \\ Malibu, CA 90265-4797
}

\begin{abstract}
We report on the development of a new microelectronic mechanical system (MEMS)-based quartz resonator technology that allows for the processing and integration of VHF to UHF high-Q oscillators and filters with high-speed silicon or III-V electronics. This paper describes the first demonstration of prototype oscillators and filters using this newly developed technology. We present impedance, $Q$, and temperature sensitivity data of UHF resonators along with phase noise and Allan deviation measurements. Our first 2-pole filter data showing low insertion loss are also presented. Finally, the results of power handling measurements are described for applications where high levels of background signals are present.
\end{abstract}

\section{INTRODUCTION}

Modern communication systems such as programmable radios and Global Positioning Satellite (GPS) receivers require ultra small, high frequency filters and oscillators with extremely good temporal and thermal stabilities, high resonant quality-factors, and excellent RF matching characteristics. Discrete bulk acoustic wave devices such as quartz resonators have been the prevailing choice for such applications because single crystal quartz has several attractive material properties. It is a low loss (high Q) piezoelectric material with zero temperature coefficient for selected crystal cuts. In addition, its chemically inert surface makes quartz a candidate for stable frequency operations. However, current manufacturing technology for quartz resonators does not provide a straightforward method for reducing the size and thereby increasing the frequency of operation into the UHF range [1]. Furthermore, integrating large arrays of precisely tuned structures with high-frequency RF electronics, and vacuum packaging the resulting chip at wafer level, are not possible with present techniques. Polysilicon surface micromachining technology has enabled the creation of on-chip UHF resonators with high $Q$ values [2]. However, these devices typically suffer from extremely large motional resistance $(>>1 \mathrm{k} \Omega)$ and temperature sensitivity, making them less desirable for low impedance, high Q RF applications.

Recent advancements in microfabrication, especially in the areas of precision wafer bonding and plasma etching, have enabled us to fabricate miniaturized quartz on-chip resonators working in the VHF-UHF frequency range. These resonators can retain the excellent properties of discrete quartz devices while providing a low-cost path for on-chip integration of filter and oscillator arrays with electronics and wafer-scale packaging.

\author{
M. K. Lim and R. T. M'Closkey \\ Mechanical \& Aerospace Engineering Dept., \\ University of California, \\ Los Angeles, CA. 90095-1597
}

\section{FABRICATION}

The quartz resonator fabrication process is illustrated in Fig. 1. The starting materials for this process are: 1) a $300-\mu \mathrm{m}-$ thick, double-side polished AT-cut single crystal quartz blank wafer, 2) a 500- $\mu$ m-thick, <100>-oriented, n-type, 1-10 ohm$\mathrm{cm}$, silicon handle wafer, and 3) a $300-\mu \mathrm{m}$-thick host substrate such as a silicon wafer. The process begins with a plasma cavity etch into the silicon handle wafer $(\sim 20 \mu \mathrm{m}$ depth) to later accommodate the top metal electrodes of the quartz wafer. The quartz wafer is metallized with electrodes (typically $800 \AA$ $\mathrm{Al}$ ) and then aligned and directly bonded to the silicon handle wafer using plasma-assisted room temperature bonding with EV Group's EV-620 aligner and EV-501 bonder. The bonded quartz is subsequently thinned to a thickness $\leq 10 \mu \mathrm{m}$ using conventional lapping and polishing techniques. Its thickness can be further reduced to less than $10 \mu \mathrm{m}$ using a $\mathrm{SF}_{6}$-based plasma etch in a Unaxis inductively-coupled, high-density plasma etcher. Veeco surface profilometer measurements of the final quartz surface after thinning give a surface roughness of $<2 \mathrm{~nm}$.

A deep reactive ion etching (DRIE) process with $\mathrm{CF}_{4}$ chemistry and bottom-side metallization $(800 \AA \mathrm{Al})$ creates the through-wafer vias and metal interconnects to bridge the topside metallization to bottom-side bonding pads. The continuous sheet of quartz is then patterned and etched using a thick Shipley SJR-5740 photoresist mask and a second DRIE step to delineate the resonator patterns. The detailed description of the DRIE process is presented in an earlier publication [3].

For the host substrate, it is first patterned and etched to create $10-\mu \mathrm{m}$-tall protrusions on its surface. Then, metals are deposited on the protrusions to form the bond pads $(200 \AA \mathrm{Ti}$ / $500 \AA \mathrm{Pt} / 5000 \AA \mathrm{Au} / 20,000 \AA \mathrm{In})$ for the subsequent thermal compression bond. In this bonding step, the Si/quartz pair is first aligned to the host substrate using EV Group's EV620 aligner and then bonded at $100^{\circ} \mathrm{C}$ in the EV-501 wafer bonder using a compression pressure of $20 \mathrm{MPa}$. Finally, the silicon handle wafer is removed using either an $\mathrm{SF}_{6}$ plasma etch or a wet TMAH process to leave the individual quartz resonators on the host substrate. An SEM image of a completed resonator is shown in Fig. 2. 


\section{Report Documentation Page}

Form Approved

OMB No. 0704-0188

Public reporting burden for the collection of information is estimated to average 1 hour per response, including the time for reviewing instructions, searching existing data sources, gathering and maintaining the data needed, and completing and reviewing the collection of information. Send comments regarding this burden estimate or any other aspect of this collection of information,

including suggestions for reducing this burden, to Washington Headquarters Services, Directorate for Information Operations and Reports, 1215 Jefferson Davis Highway, Suite 1204, Arlington

VA 22202-4302. Respondents should be aware that notwithstanding any other provision of law, no person shall be subject to a penalty for failing to comply with a collection of information if it

does not display a currently valid OMB control number.

\begin{tabular}{|c|c|c|}
\hline $\begin{array}{l}\text { 1. REPORT DATE } \\
\mathbf{2 0 0 5}\end{array}$ & $\begin{array}{l}\text { 2. REPORT TYPE } \\
\text { N/A }\end{array}$ & $\begin{array}{l}\text { 3. DATES COVERED } \\
\text { - }\end{array}$ \\
\hline \multirow{3}{*}{\multicolumn{2}{|c|}{$\begin{array}{l}\text { MEMS-Based Quartz Oscillators and Filters for On-Chip Integration } \\
\text { MEMTL }\end{array}$}} & 5a. CONTRACT NUMBER \\
\hline & & 5b. GRANT NUMBER \\
\hline & & 5c. PROGRAM ELEMENT NUMBER \\
\hline \multirow{3}{*}{\multicolumn{2}{|c|}{ 6. AUTHOR(S) }} & 5d. PROJECT NUMBER \\
\hline & & 5e. TASK NUMBER \\
\hline & & 5f. WORK UNIT NUMBER \\
\hline \multicolumn{2}{|c|}{$\begin{array}{l}\text { 7. PERFORMING ORGANIZATION NAME(S) AND ADDRESS(ES) } \\
\text { Sensors and Materials Laboratory HRL Laboratories LLC Malibu, CA } \\
\text { 90265-4797 }\end{array}$} & $\begin{array}{l}\text { 8. PERFORMING ORGANIZATION } \\
\text { REPORT NUMBER }\end{array}$ \\
\hline \multirow{2}{*}{\multicolumn{2}{|c|}{ 9. SPONSORING/MONITORING AGENCY NAME(S) AND ADDRESS(ES) }} & 10. SPONSOR/MONITOR'S ACRONYM(S) \\
\hline & & $\begin{array}{l}\text { 11. SPONSOR/MONITOR'S REPORT } \\
\text { NUMBER(S) }\end{array}$ \\
\hline
\end{tabular}

12. DISTRIBUTION/AVAILABILITY STATEMENT

Approved for public release, distribution unlimited

13. SUPPLEMENTARY NOTES

... C. Nguyen text 07-37-122 MEMS-Based Quartz Oscillators and Filters for On-Chip Integration; R. Kubena, F. Stratton, D. Chang, R. Joyce, T. Hsu, M. Lim, ... tycho.usno.navy.mil/ptti/index7.html -, The original document contains color images.

14. ABSTRACT

15. SUBJECT TERMS

16. SECURITY CLASSIFICATION OF:

a. REPORT

unclassified b. ABSTRACT

unclassified c. THIS PAGE

unclassified
17. LIMITATION OF ABSTRACT

SAR
18. NUMBER

OF PAGES

6 19a. NAME OF

RESPONSIBLE PERSON 


\section{Starting Materials}

2. Etch Cavities in Si
3. Pattern \& Metallize
Top Electrodes on
Quartz

4. Bond Quartz to Si Handle
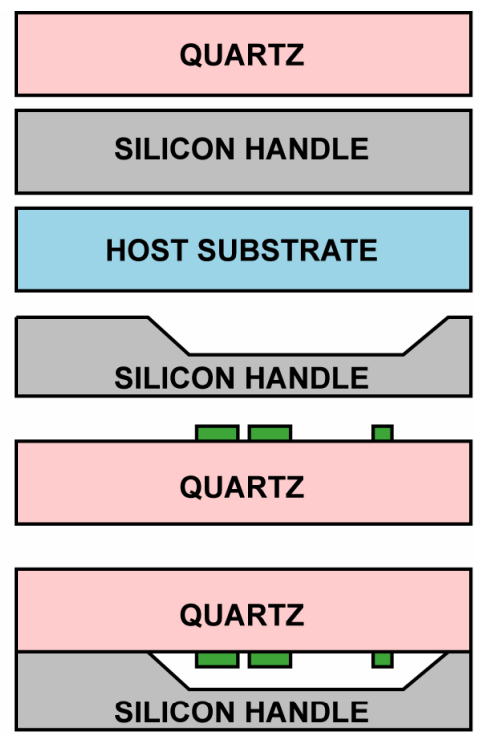

\section{Thin Quartz to $<10 \mu \mathrm{m}$}

\section{Pattern \& Metallize Via Holes in Quartz}

\section{Pattern \& Metallize Bottom Electrodes on Quartz}

8. Pattern \& Etch Quartz Resonator

\section{Etch Protrusion in Host Substrate}

10. Pattern \& Metallize Bond Pads
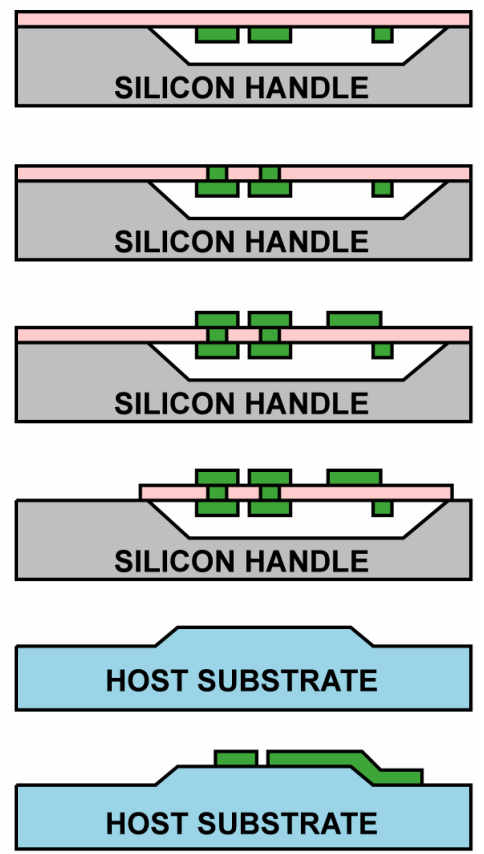

\section{Bond Si/Quartz} to Host Substrate

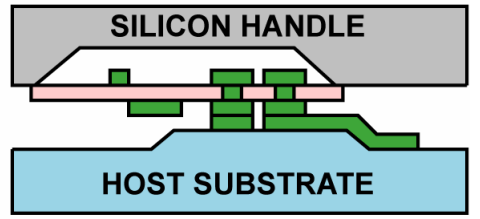

\section{Remove Si} Handle

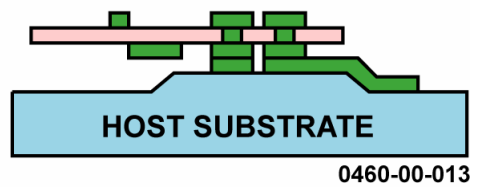

Figure 1. Fabrication process flow for the quartz resonators.

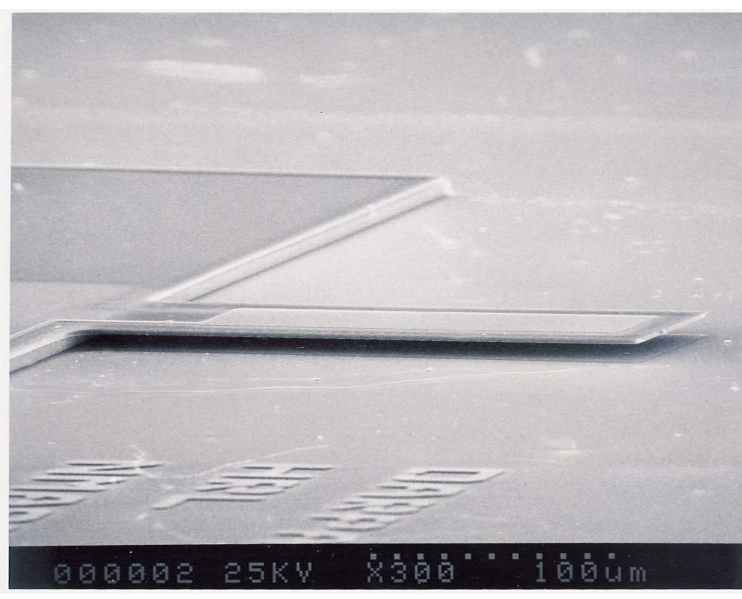

Figure 2. SEM photograph of a completed UHF resonator. Quartz thickness $=2 \mu \mathrm{m}$.

This fabrication process provides a path for integrating large resonator arrays with high frequency RF electronics since the low-temperature process is compatible with standard silicon and III-V compound semiconductor processes. This process also allows conventional packaging techniques with solder bonding to hermetically seal the resonators at the wafer level. The permanent Au-In thermal compression bond for the resonators can withstand post-processing temperatures $\left(>160^{\circ} \mathrm{C}\right)$ which allow for low temperature sealing.

\section{RESONATOR RESULTS}

Several different designs of AT-cut shear-mode resonators have been tested using Cascade microprobes and an Agilent 4991A impedance analyzer at room temperature. Many of these results have been reported previously [4]. Our newest results indicate that resonators with fundamental mode resonant frequencies approaching $3 \mathrm{GHz}$ can be fabricated with these basic techniques. Fig. 3 shows the impedance plot of a $0.65-\mu \mathrm{m}$-thick shear-mode resonator with dimensions of $40 \times$ $60 \mu \mathrm{m}^{2}$ with a fundamental frequency of $1.94 \mathrm{GHz}$. A Q of 7,248 and a motional resistance of $600 \Omega$ were measured for this device in air. This yields an $\mathrm{f} \times \mathrm{Q}$ product of $1.4 \times 10^{13} \mathrm{~Hz}$, close to the expected limit for AT-cut quartz devices [5]. Larger devices had motional resistances $<50 \Omega$ at similar frequencies but with some anharmonic modes.

\section{A. Temperature Dependence}

As reported previously, the temperature dependence of our first generation resonators was affected by bonding stresses at the $\mathrm{Si}$ substrate interface [4]. Using a $300^{\circ} \mathrm{C} \mathrm{Au}$-to-Au thermal compression bond, residual stress levels of several $\mathrm{MPa}$ were possible in the active areas of our designs. This produced frequency shifts of approximately $+23 \mathrm{ppm} /{ }^{\circ} \mathrm{C}$ for AT-cut angles of 35.75 degrees.

In order to reduce the bonding stress effects, we recently implemented a lower temperature Au-In bond to the substrate. Visually, we noted a complete elimination of optical stress fringes around the bonding pads with the lower temperature bond. Using AT-cut angles of 35.25 deg., we have now 
obtained near theoretical temperature compensated behavior. The frequency versus temperature data for a shear-mode disk design is presented in Fig. 4 showing 23 ppm stability over the entire $25^{\circ}$ to $100^{\circ} \mathrm{C}$ range. Hysteresis data obtained during temperature cycling indicated a shift of about $2 \mathrm{ppm}$ after temperature ramping as shown in Fig. 5.
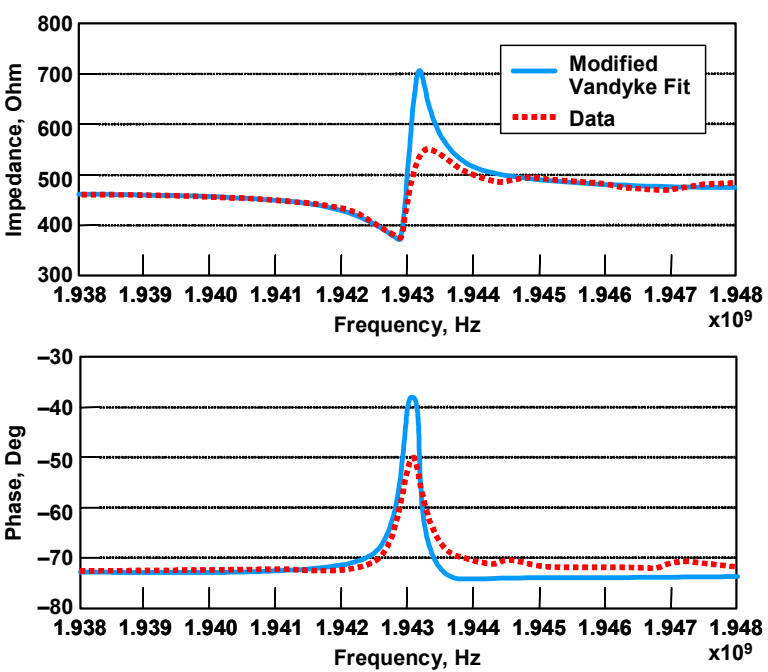

Figure 3. Impedance and phase plots for $1.94 \mathrm{GHz}$ quartz resonator in air. $\mathrm{C}_{\mathrm{o}}$ $=1.83 \times 10^{-13} \mathrm{f}, \mathrm{C}_{1}=1.88 \times 10^{-17} \mathrm{f}, \mathrm{L}_{1}=3.56 \times 10^{-4} \mathrm{~h}, \mathrm{R}_{1}=600 \Omega$, and $\mathrm{Q}=$ 7,247 in air. Dotted curve is measured data while the solid curve is a modified Van Dyke fit.

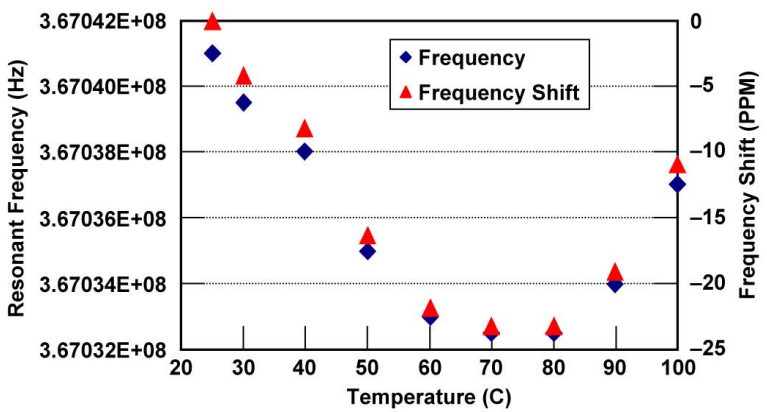

Figure 4. Temperature sensitivity of resonators utilizing Au-In bonding to the substrate.

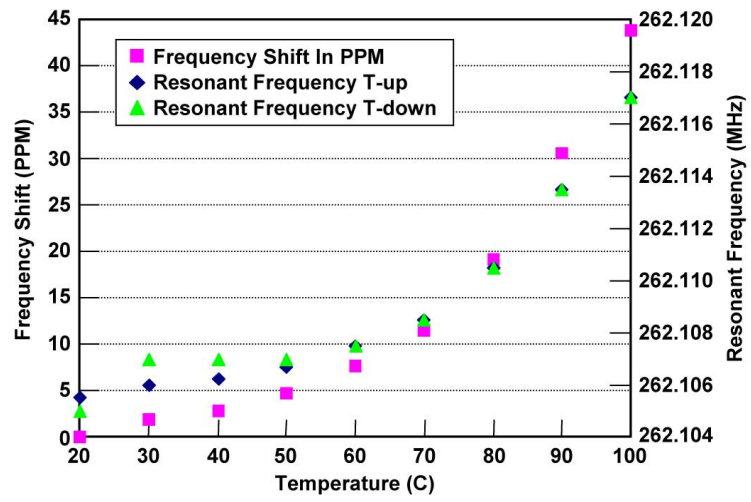

Figure 5. Hysteresis data for a 300- $\mu \mathrm{m}$-diameter shear mode resonator.

\section{B. Power Handling}

We have made measurements for determining the power handling capabilities of our resonators both for in-band and out-of-band conditions. Since our resonators are significantly smaller than commercial devices, one might expect that their power handling capabilities would be reduced. However, tests to date have indicated that they are surprisingly robust.

For our first tests, the power handling was measured in air in a microwave package using a $545-\mathrm{MHz}, 160 \times 50 \mu \mathrm{m}^{2}$ resonator with a $\mathrm{Q}$ of 13,000 . Power was applied directly from a network analyzer, and we observed the forward reflection $\left(\mathrm{S}_{11}\right)$ as a function of applied power with the resonator output shorted. Small nonlinear behavior was observed with an input power of $400 \mu \mathrm{W}$ which corresponds to a current density of about $28 \mathrm{~A} / \mathrm{cm}^{2}$ on resonance. These data are shown in Fig. 6.

A similar test on a commercial $250-\mathrm{MHz}$ resonator with an electrode area of $700 \times 700 \mu \mathrm{m}^{2}$ showed nonlinear behavior around 1-2 $\mathrm{mW}$ or a current density of about $1.5 \mathrm{~A} / \mathrm{cm}^{2}$. Thus, the MEMS resonator showed similar power handling capabilities compared to larger commercial units.

Our next tests were designed to simultaneously apply high RF power to the devices at arbitrary frequencies while observing the transmission characteristics with a network analyzer using a combiner at the device input. We used a commercial $3-\mathrm{W}$ RF power amplifier to apply power to the resonators and monitored this input power with an Agilent EPM series power meter using a $\times 1000$ attenuator. Various isolators were used to protect the instruments from reflected power. The test set-up contributed to about $-13 \mathrm{~dB}$ of scanning transmission loss for the network analyzer. Fig. 7 shows the transmission characteristics as a function of RF power applied $0.9 \%$ off the center frequency. A noticeable shift in frequency was observed only for the highest power level applied of 2.3 W.

S11 Forward Reflection

Log Magnitude Ref $=0.000 \mathrm{~dB} \quad 2.000 \mathrm{~dB} / \mathrm{DIV}$
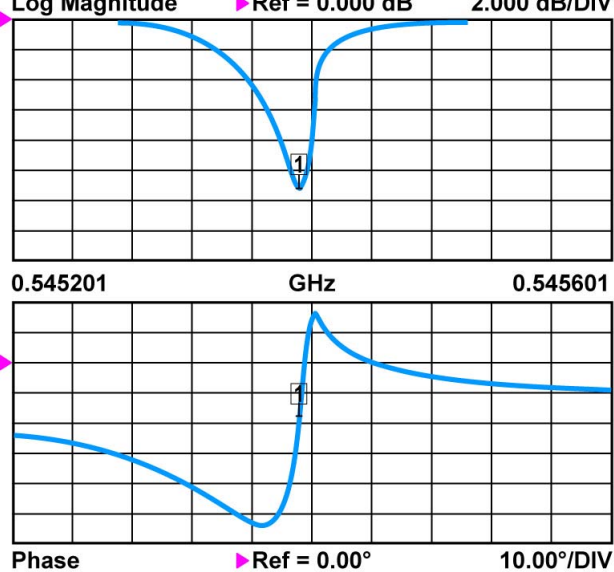

Test Signals

Power control

$3.00 \mathrm{~dB}$ $(0$ to $-20.000 \mathrm{~dB})$

Port 1 Attn $0 * 10 \mathrm{~dB}(0-70)$

Port 1 Power $-4.00 \mathrm{dBm}$

Port 2 Attn $0 * 10 \mathrm{~dB}(0-40)$

Calibrate

For Flatness (CAL Exisis)

Flatness Correction at $-4.00 \mathrm{dBm}$ Source 2 PWR $-4.00 \mathrm{dBm}$

Previous Menu

Press <Enter> To Select Or Turn On/Of

Figure 6. Forward reflection $\left(\mathrm{S}_{11}\right)$ data for a MEMS-resonator with an input power of $400 \mu \mathrm{W}$. A small nonlinear behavior was noted at this power level. 


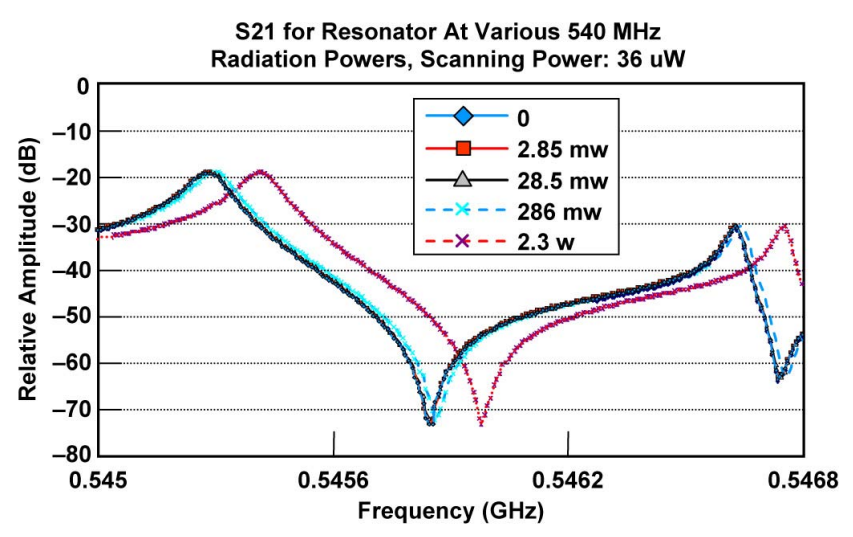

Figure 7. $\mathrm{S}_{21}$ for a 546-MHz resonator for various RF input powers applied $0.9 \%$ off the resonant frequency.

Since the resonators in these tests were not temperature compensated, we could easily use the observed frequency shifts as a function of applied power as indicators of the temperature increase. Assuming a maximum temperature for possible damage of the chip of around $300^{\circ} \mathrm{C}$, one can calculate that the maximum on-resonance power for our resonators is about $+15 \mathrm{dBm}$ while the maximum off-resonance power is $+49 \mathrm{dBm}$. Using temperature compensated resonators, the frequency shifts noted in Fig. 7 would obviously be substantially reduced.

\section{OSCILLATOR RESULTS}

In order to demonstrate the ability to utilize miniaturized MEMS-based quartz resonators for on-chip frequency standards, prototype oscillator circuits were modeled, fabricated, and tested. We found that the specific construction of the boards was critical for minimizing the parasitic capacitance around the resonator. Copper-clad Duroid boards were utilized with the copper cladding removed from the local area around the resonator. This reduced the parasitic capacitance. The resonators were wire bonded to the circuit and tested in air. A photograph of a Pierce oscillator circuit is shown in Fig. 8, and a wire bonded resonator is shown in Fig. 9.

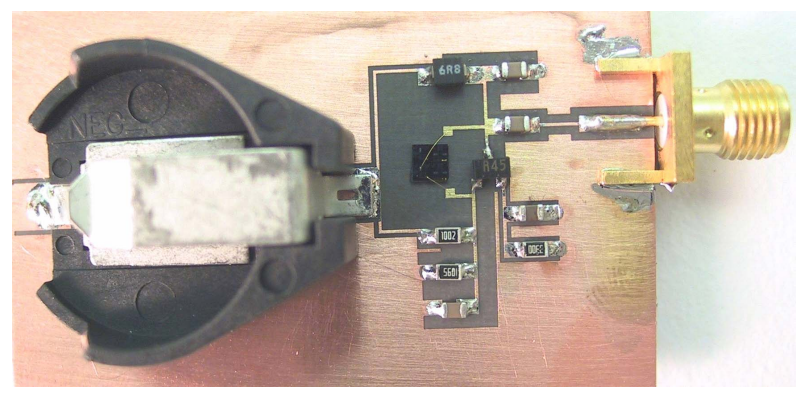

Figure 8. Photograph of surface mount prototype UHF oscillator board. A battery holder is on the left.

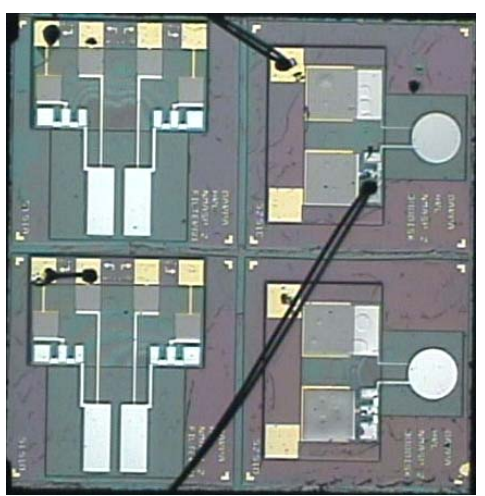

Figure 9. The wire-bonded MEMS resonator/filter chip used in the oscillator circuit shown in Figure 8. The wire bonded resonator is a $300-\mu \mathrm{m}$-diameter shear-mode disk design.

Allan deviations of the oscillators were obtained using a 10 digit counter with sampling rates of roughly $10 \mathrm{~Hz}$. Then $325 \mathrm{MHz}$ oscillators were mounted on a hot plate in air with a temperature resolution of $\pm 0.5^{\circ} \mathrm{C}$. Both non-temperature compensated (resonators bonded to the substrate using a Au-to$\mathrm{Au}$ thermal compression bond) and temperature compensated resonators were tested. The results are shown in Fig. 10. Note the improvement in stability for the temperature compensated devices. Future tests under vibration and in vacuum may provide indications of the ultimate performance without degrading environmental factors.

Phase noise measurements were also performed on the oscillators without temperature regulation and in air using an Agilent E5052A phase noise unit. The phase noise is shown in Fig. 11. In addition, a counter was used to set an Agilent E8257D reference frequency standard to the carrier frequency of the MEMS oscillator. The phase noise of the Agilent reference standard with an internal SC-cut, $10-\mathrm{MHz}$ ovenized, and vibration isolated oscillator is also shown in Fig. 11 for comparison. Note, at a roughly $3-\mathrm{kHz}$ offset frequency, the MEMS oscillator is comparable to the reference standard. The MEMS oscillator noise floor approaches $-160 \mathrm{dBc} / \mathrm{Hz}$ beyond $10^{5}$ offset frequency and is limited by electronic noise from the transistor of the sustaining circuit. At low offset frequencies, the noise of the MEMS oscillator follows a $1 / \mathrm{f}^{3}$ dependence.

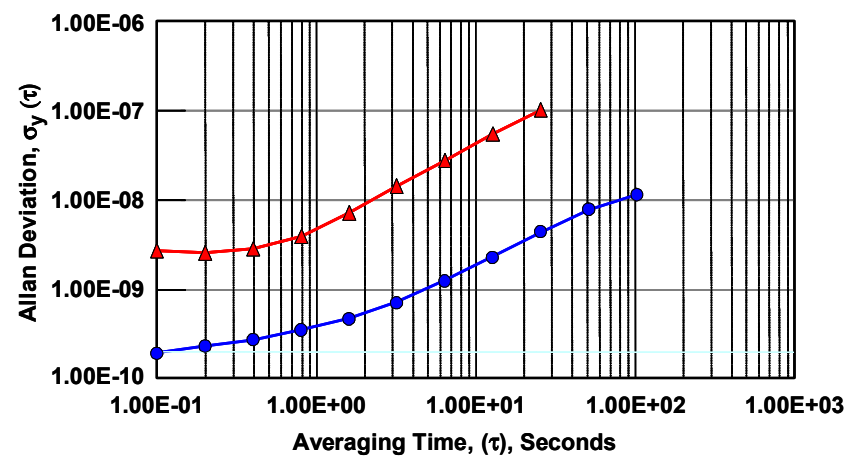

Figure 10. Allan deviations of the noise for two 325-MHz MEMS oscillators. The data in triangles is for a non-temperature compensated resonator while the data in circles is for a temperature compensated resonator. 


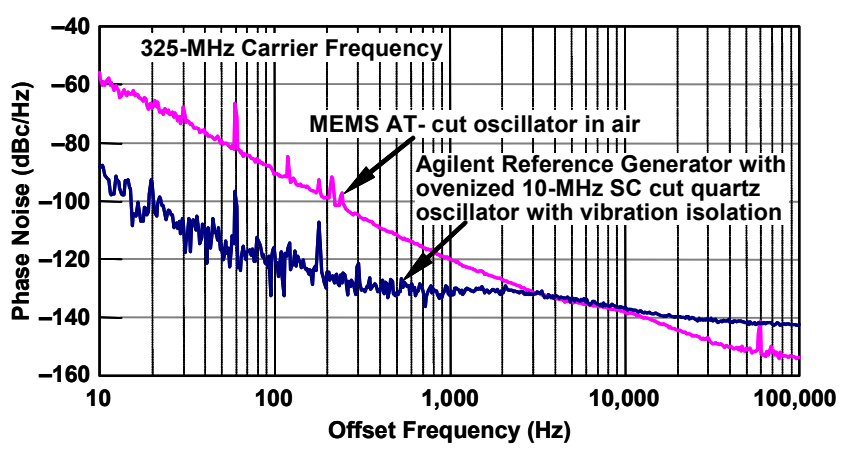

Figure 11. Phase noise for a MEMS AT-cut oscillator in air compared to a commercial Agilent frequency reference standard, both operating at $325 \mathrm{MHz}$

\section{FILTER RESULTS}

Monolithic crystal filters have been fabricated using the design methodology described previously [4]. Two and three pole filters were designed for the frequency range between 200-300 MHz. An SEM microphotograph of the $400 \times 160$ $\mu \mathrm{m}^{2} \mathrm{Al}$ electrodes on a flat quartz slab is shown in Fig. 12. Acoustic gaps between $20-80 \mu \mathrm{m}$ were tested. The bandwidth increased for smaller acoustic gaps as expected from conventional design rules [6]. $S_{21}$ and $S_{11}$ are presented in Fig. 13 for a two-pole filter with a $20 \mu \mathrm{m}$ acoustic gap. The $3 \mathrm{~dB}$ bandwidth was $85 \mathrm{kHz}$ or $0.04 \%$ of the center frequency, which closely matches the expected bandwidth for a matching input/output impedance of $1 \mathrm{k} \Omega[6]$. We measured an insertion loss of $-0.35 \mathrm{~dB}$ and isolation of roughly $-40 \mathrm{~dB}$. Two anharmonic transmission peaks roughly $-10 \mathrm{~dB}$ down were observed at a few megahertz above the center frequency. Optimized designs for absorbing or attenuating these extraneous modes are expected to significantly reduce the level of the spurious transmission peaks [7].
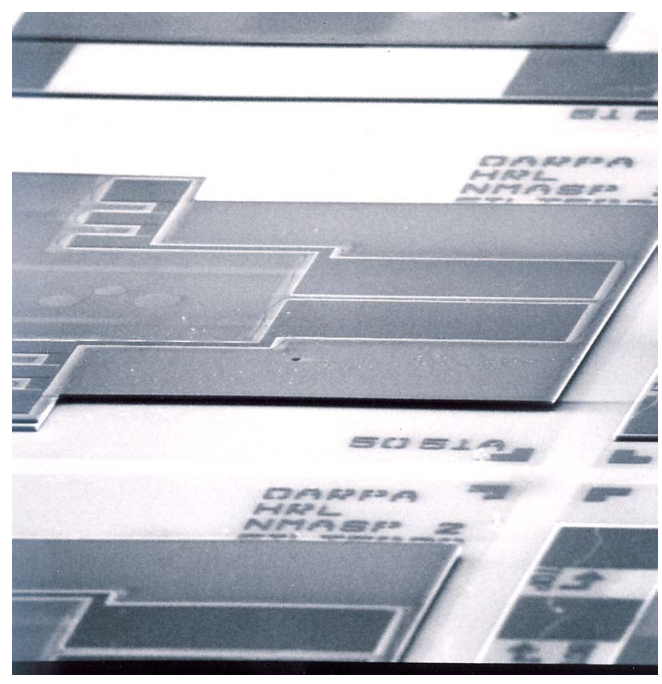

Figure 12. An SEM of a filter array with various bandwidths.

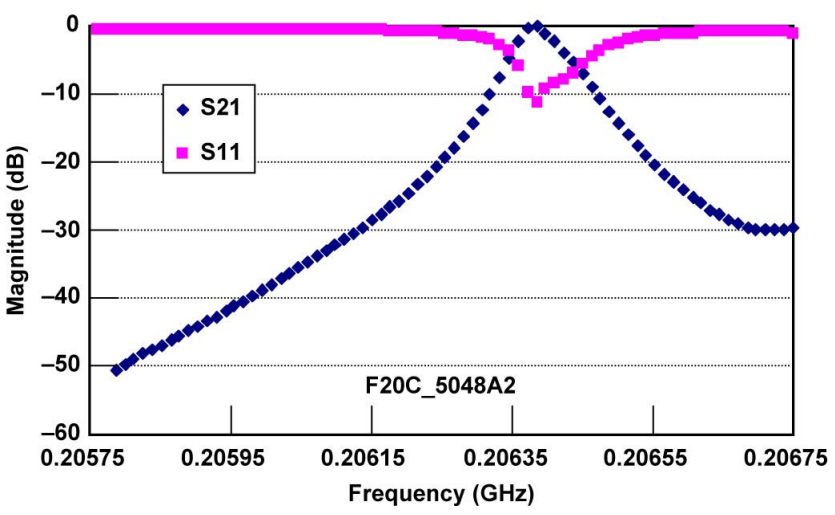

Figure 13. Transmission and forward reflection power of a $206-\mathrm{MHz}$ MEMS two-pole filter.

\section{CONCLUSIONS}

We have developed a new VHF-UHF quartz resonator technology that can be integrated with RF electronics and is compatible with MEMS-based wafer-scale vacuum packaging. Fundamental mode operation above $2 \mathrm{GHz}$ has been demonstrated with Q's of 7,200 in air. By maintaining low bonding stress at the quartz/Si interface, we have demonstrated temperature sensitivities comparable to commercial AT-cut quartz resonators. Surface mount prototype UHF oscillators have been constructed with a phase noise in air of -120 $\mathrm{dBc} / \mathrm{Hz} @ 1 \mathrm{kHz}$ offset frequency and an Allan deviation of $4 \times 10^{-10}(\tau=1 \mathrm{sec})$. Two-pole monolithic crystal filters at $206-\mathrm{MHz}$ center frequency have shown extremely low insertion loss of $-0.35 \mathrm{~dB}$ and near the expected bandwidth $(0.04 \%)$ with $1 \mathrm{k} \Omega$ matching impedance. Power handling of these miniaturized filters is comparable to other on-chip electronic circuits. We expect that with further manufacturing development, this technology can be utilized in future communication systems requiring multiple frequency channels, low power, and small size. In addition, new radio architectures are enabled with arrays of ultra narrow band filters.

\section{ACKNOWLEDGMENTS}

The authors would like to thank Dr. John Vig of U.S. Army CECOM for his valuable technical discussions and support. This work was funded by DARPA's Microsystems Technology Office under contract DAAB07-02-C-P613.

\section{REFERENCES}

[1] Statek Corporation, Technical Note 28, Rev. A, "An ultraminiature low-profile AT quartz resonator.'

[2] C. T.-C. Nguyen, "Frequency-selective MEMS for miniaturized low-power communication devices," IEEE Transactions on Microwave Theory and Techniques, Vol. 47, No. 8, pp. 1486-1503, 1999.

[3] D. Chang, F. Stratton, R. Kubena, R. Joyce, "Optimized DRIE etching of ultra-small quartz resonators," Proceedings of the 2003 IEEE International Frequency Control Symposium, pp. 829-832, 2003.

[4] F. P. Stratton, D. T. Chang, D. J. Kirby, R. J. Joyce, T-Y Hsu, R. L. Kubena, Y-K Yong, "A MEMS-based quartz resonator technology for $\mathrm{GHz}$ applications," Proceedings of 
the 2004 IEEE International Frequency Control Symposium, pp. 27-34, 2004.

[5] R. Smythe and R. Angove, "Chemically-milled UHF SCcut resonators," Proceedings of the 1988 IEEE International Frequency Control Symposium, pp. 73-77, 1988.

[6] R. A. Sykes and W. D. Beaver, "High frequency monolithic crystal filters with application to single frequency and single sideband use," Proceedings of the $20^{\text {th }}$ Ann. Freq. Control Symposium, pp. 288-308, 1966.

[7] M. Onoe, H. Jumonji, and N. Kobori, "High frequency crystal filters employing multiple mode resonators vibrating in trapped energy modes," Proceedings of the $20^{\text {th }}$ Ann. Freq. Control Symposium, pp. 266-287, 1966. 